Original Research Paper

\title{
An Empirical Study on E-Learning versus Traditional Learning among Electronics Engineering Students
}

\author{
Wai Kit Wong and Poh Kiat Ng \\ Faculty of Engineering and Technology, Multimedia University, Jln Ayer Keroh Lama, 75450 Malacca, Malaysia
}

\author{
Article history \\ Received: 13-03-2016 \\ Revised: $15-04-2016$ \\ Accepted: 04-06-2016 \\ Corresponding Author: \\ Poh Kiat Ng \\ Faculty of Engineering and \\ Technology, Multimedia \\ University, Jln Ayer Keroh \\ Lama, 75450 Malacca, \\ Malaysia \\ Email: pkng@mmu.edu.my
}

\begin{abstract}
In academia, it appears that many lecturers are still contented in using traditional lecturing methods. Cultivating the use of e-learning requires proper understanding of its difference with traditional learning. In this study, the difference between e-learning with traditional learning was descriptively and empirically investigated, with an emphasis on a module in Electronics Engineering known as Fundamentals of Operational Amplifier. This research involved first-year electronics engineering students from the Faculty of Engineering and Technology, Multimedia University Malaysia. Upon completion of the module, they were asked to participate in a survey and quiz. The data collected were analysed using the normality, reliability and Analysis Of Variance (ANOVA) tests. It was found that e-learners had significantly different results compared to traditional learners. They also exhibited better performance and agreeability in the quiz and survey respectively. In concurrence with the findings of previous researchers, this study suggested that graphical lessons can have a substantial effect on the acceptance of e-learning. The findings of this study can be used to not only improve the course design on Fundamentals of Operational Amplifier but also as a platform to develop greater and more effective learning outcomes in Electronics Engineering and other fields. Generally, although more analyses may be required to verify the existing findings in e-learning, this study can still serve as precursory information regarding the flexibility and effectiveness of e-learning in electronics engineering courses.
\end{abstract}

Keywords: E-Learning, Lecturing, Fundamentals of Operational Amplifier, Traditional Learning, Electronics Engineering

\section{Introduction}

In recent years, there has been an increased focus on e-learning. In engineering education, previous studies generally found a positive relationship between traditional learning and e-learning (Rodríguez et al., 2013; Soler, 2010; Soler et al., 2006; Ubell, 2000). Previous developments on e-learning have involved computer-based assessment platforms for teaching and learning, Artificial Intelligence applications and autocorrect functions in e-learning platforms (Rodríguez et al., 2013; Soler, 2010; Soler et al., 2006).

However, it appears that these studies on e-learning have yet to examine the impacts of using video demonstrations to prove the derivations of circuit designs and circuit analyses, both of which are topics covered in most electronics engineering subjects. Many lecturers in electronics engineering are reluctant to change their traditional methods in delivering lectures as they refuse to leave their comfort zone of Power Points and slides. In addition, proving derivations of circuit designs and circuit analyses is still done by many lecturers manually (for instance, with marker pen writings on the whiteboard). These lecturers may feel that it is much of a hassle to integrate technology into their lectures. Moreover, the proofs of derivations and analyses are only written and explained once in a traditional classroom. If students were to miss that particular class, they have to either figure out the derivations on their own afterwards or just be left 
incapable of attempting such derivations or analyses. Consequently, the learning in this case becomes very teacher-centred (or in other words, traditional), where students rely very much on their lecturers and work is done alone with little to no collaborations.

Hence, this study proposes a new e-learning module known as FUNDA OP-AMP specifically for learning the subject Fundamentals of Operational Amplifier in Electronics Engineering. This e-learning module is developed in order to inculcate students and lecturers with 21 st century learning. This module demonstrates the processes of derivations in circuit designs and analyses through videos. With this module, the work steps can be played back as many times as the students want. If students were unsure of an important section on derivation in class, they would be able to go through this module to clarify the uncertainty. Their understanding can also be improved by going through the module several times.

This study involved 2 groups of students, namely the e-learning group (exposed to the FUNDA OPAMP module) and the traditional learning group (exposed to traditional lecture methods). The elearning group was to be engaged in a more studentcentred manner. The FUNDA OP-AMP module was released to the e-learning group prior to the actual lecture class in order for this group of students to do some self-learning at home before they come to class. In the lecture class, this group was allowed to speak out their doubts and uncertainties on the subject faceto-face with the lecturer/instructor both individually and in group discussions.

\section{Literature Review}

The definition of e-learning has evolved over the past few decades and continues to change. Although the origin of the term is uncertain, it is believed that its first use was in 1999 when a computer and software company in Atlanta offered and labelled their online courses coupled with live instruction as e-learning (Friesen, 2015). This definition suggested that e-learning was restricted to only virtual learning without face-to-face intervention, a constraint that has become less true with the later development of e-learning.

It is important to make aware of the purpose of elearning. Apart from improving students' performance and cost effectiveness, e-learning also aims to be highly personalised for each learner. This has been suggested by Thorne (2003) when he described elearning as the process of engaging the ordeals of customising learning and development to the necessities of students. In order to meet the objectives of e-learning, social interaction in a traditional classroom is equally as important as the utilisation of an individualised online system.

According to Ubell (2000), one of the first approaches in e-learning involves databases knowledge, which is an underlying subject in computer engineering. In 2006, the technical engineering team in computer management and systems in the University of Girona found that the use of e-learning platforms not only increased the students' motivations in studies but also improved their academic results (Soler et al., 2006). The most relevant achievement in this study was a tool that autocorrects the exercises related to the subject. This tool allowed teaching staffs to realise and acknowledge the learning level and possible deficiencies of the students.

Some developments included a Computer-Based Assessment (CBA) e-learning platform distinguished by the automation of every teaching/learning feature of the student (Soler, 2010). With the CBA, it was found that an interaction existed between the lecturer and engineering students all along the evaluation process. In this process, the delivery of the course exercises, its correction and the feedback generated is performed by the system automatically. Rodríguez et al. (2013) proposed that the Artificial Intelligence techniques were integrated into the e-learning platform of the engineering laboratory practices (System and Automation Engineering Laboratories) to form a teacher-cognitive system combination.

E-learning can be used together with the traditional face-to-face learning as well. This mode of learning would then be known as blended learning. Many studies concur that blended learning is a hybrid mode of learning which harnesses both face-to-face learning and online learning (Bersin, 2004; Boyle et al., 2003; Garrison and Vaughan, 2008; Lim and Morris, 2009; Mortera-Gutierrez, 2006). For example, Graham (2006) in the first handbook of blended learning defined blended learning as the combination of two historically separate models of teaching and learning, namely the traditional face-to-face learning systems and distributed learning systems. It is worth noting that the term distributed learning systems is an umbrella term for any technology-led learning. Elearning can go hand-in-hand with traditional learning since it combines the Internet and digital media with conventional classroom structures which necessitates the physical co-presence of the learners and educator (Friesen, 2015).

\section{FUNDA OP-AMP E-Learning Module}

This section demonstrates the implementation of the FUNDA OP-AMP module. This module is created using the mixture of several functions, namely Lecture MAKER NS, Video Scribe and Camtasia Studio 8. The complete version is found in an executable file (.exe 
format). Learners are able to access the courses at any computer using either a Windows or Linux operating system. The developed FUNDA OP-AMP e-learning module contains lecture notes, video demonstrations on derivations of circuit designs and circuit analyses, laboratory work video demonstrations (to encourage evidence-based learning), tutorial examples and a quiz with an autocorrect function to allow students to instantaneously learn from their mistakes.

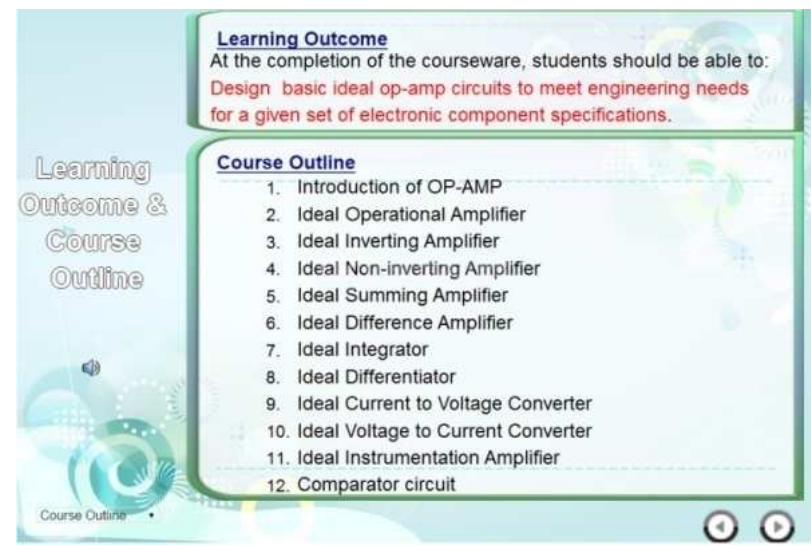

(a)

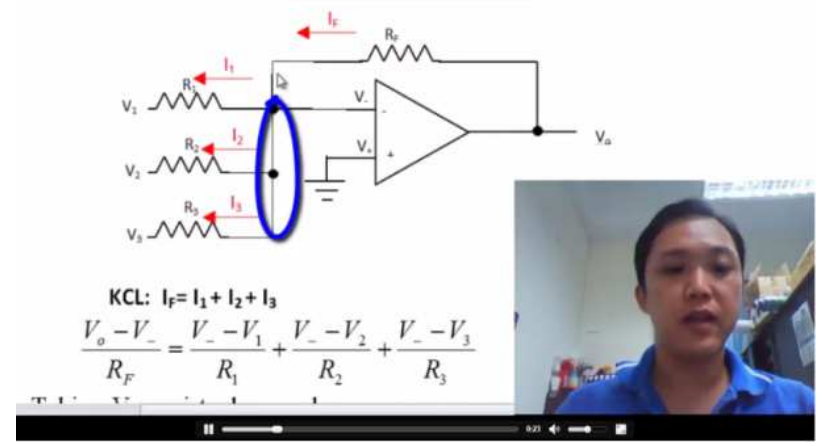

(c)

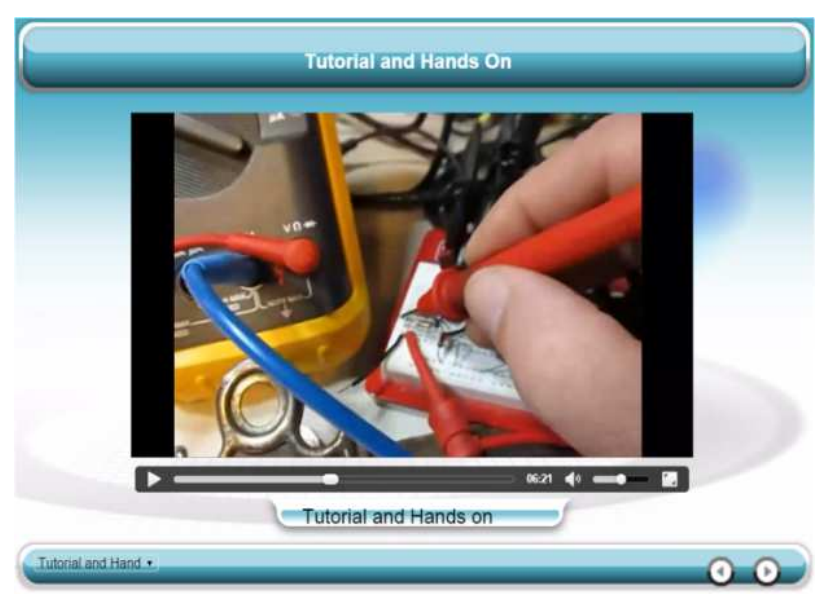

(e)
Figure 1 shows some screenshots of the FUNDA OPAMP module. The module's content page is shown in Fig. 1a. The syllabus covers topics such as the introduction of Op-Amp, ideal operational amplifier, ideal inverting amplifier, ideal non-inverting amplifier, ideal summing amplifier, ideal difference amplifier, ideal integrator, ideal differentiator, ideal current to voltage converter, ideal voltage to current converter, ideal instrumentation amplifier and comparator circuit.

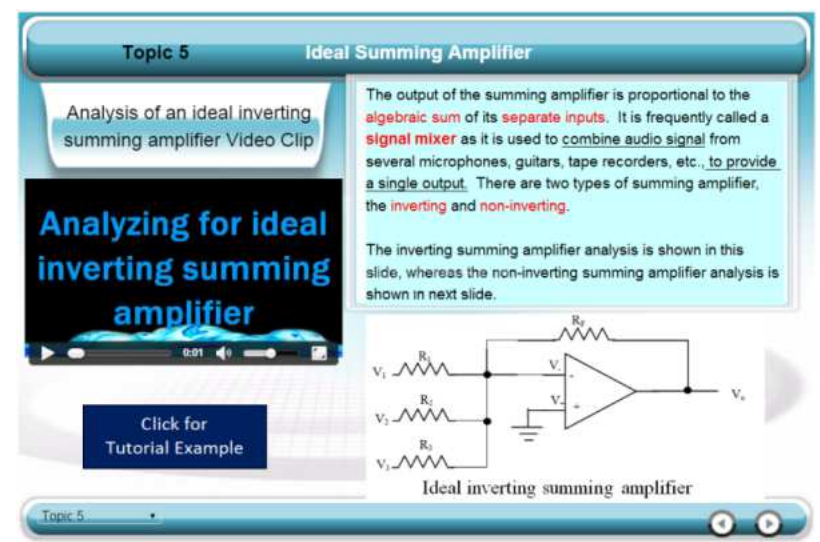

(b)

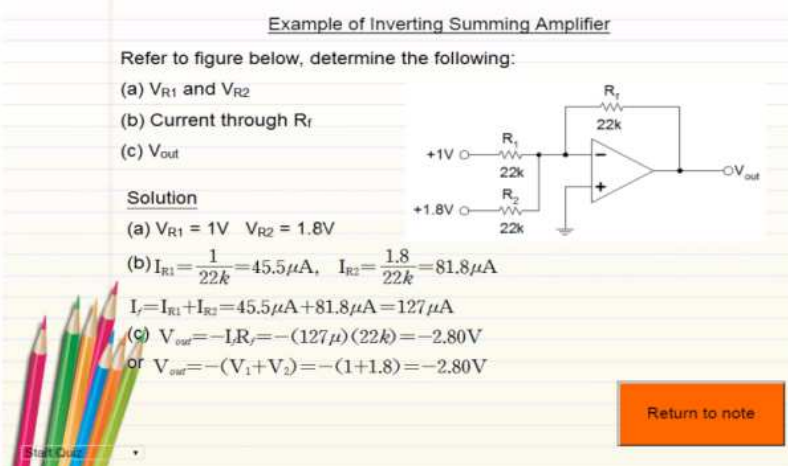

(d)

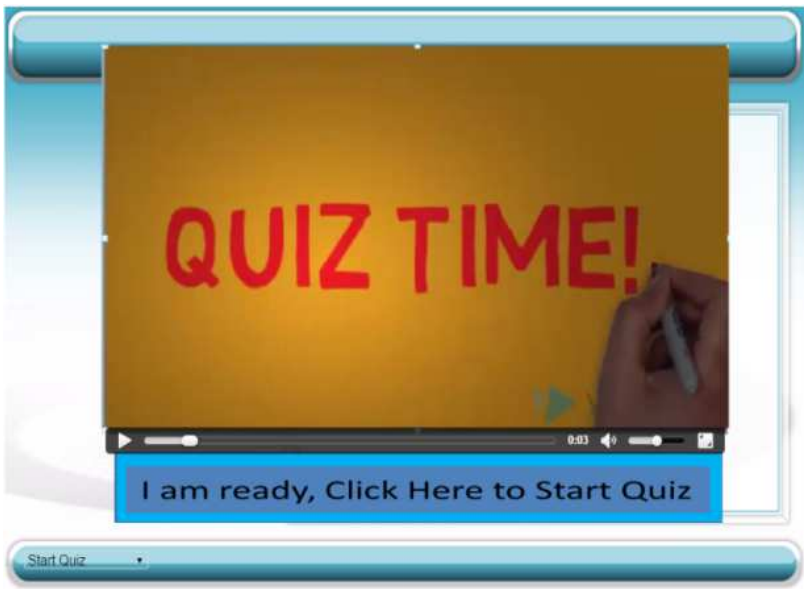

(f) 


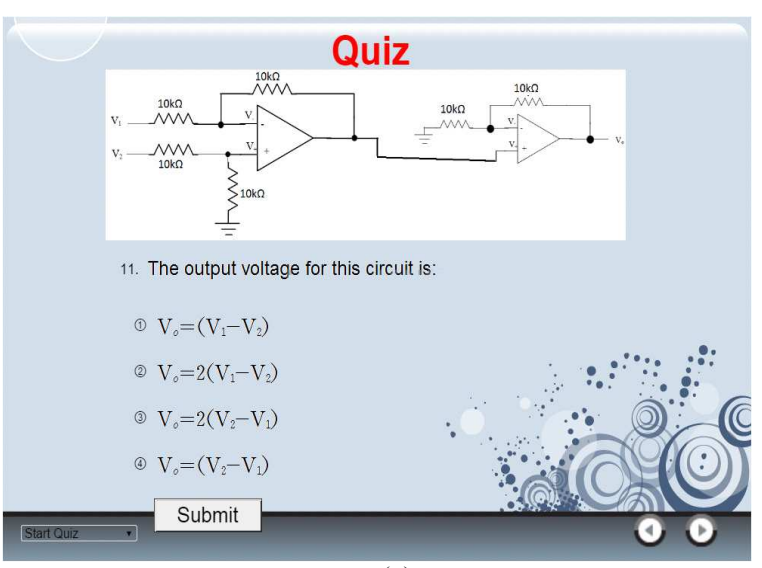

(g)

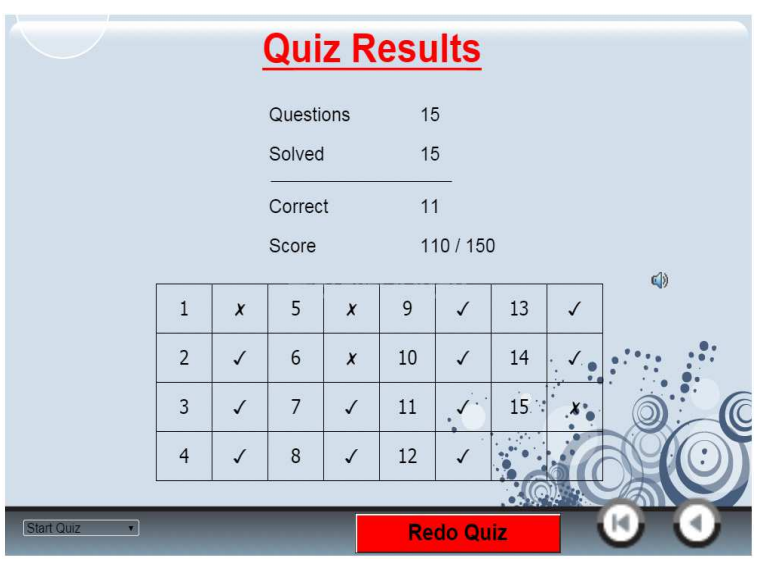

(h)

Fig. 1. Screenshots of the FUNDA OP-AMP Module; (a) Content Page of FUNDA OP-AMP Module; (b) Topic Example on the Ideal Summing Amplifier; (c) Video Guide for Step-By-Step Analysis and Derivation; (d) Tutorial Example; (e) Hands-on Laboratory Work; (f) Starting Page of Quiz; (g) Quiz Example Page; (h) Quiz Result Page

An example of a topic under the ideal summing amplifier is shown in Fig. 1b. The right-hand side covers the lecture notes for self study, while the left-hand side demonstrates a video guide to help the learners conduct a step-by-step analysis and derivation. This demonstration also contains face-to-face explanation with the instructor's face shown at bottom right of the screen as shown in Fig. 1c. Furthermore, a button is placed at the left-hand corner of Fig. $1 \mathrm{~b}$ to link the learners to a tutorial example shown in Fig. 1d.

After covering all the twelve topics, the learners are directed to conduct $6 \mathrm{~min}$ long hands-on laboratory work as shown in Fig. 1e. The learners are instructed to prepare the components and measuring tools as demonstrated in the video and follow the step-by-step procedures given to conduct an experimental validation on the designed opamp circuits and collect results.

The e-learning module ends with a quiz of fifteen questions, with both multiple choice and subjective questions included. The starting page of the quiz is shown in Fig. 1f. An example of a quiz question is shown in Fig. $1 \mathrm{~g}$ while the quiz result page is shown in Fig. $1 \mathrm{~h}$. If the answer provided by a learner to a question is found to be incorrect, he/she is allowed to redo that particular question in order to learn from his/her mistake.

\section{Methodology}

This study is divided into two stages, namely the survey stage and the experimental stage. The participants, who are electronics engineering students are divided into 3 types of majoring, namely:

- BEng (Hons) Electronics majoring in Telecommunications

- BEng (Hons) Electronics majoring in Robotics and Automation

\section{- BEng (Hons) Electronics majoring in Bio- Instrumentation}

The participants are also differentiated by their gender (male or female) and status (repeater or nonrepeater of the module). For both the survey and experimental stage, the participants are divided into two groups, namely the FUNDA OP-AMP group and the traditional learning group. The module delivered to both groups is known as the fundamentals of operational amplifiers. The FUNDA OP-AMP group is taught using e-learning strategies while the traditional learning group is taught using traditional lecturing strategies.

Each of the groups consist of 30 participants. For the survey stage, surveys on the lecturing methods are distributed to both groups at the end of the module. For the experimental stage, students of both groups are instructed to sit for a test on the fundamentals of operational amplifiers at the end of the module. The normality and reliability of the data are inspected before the parametric analyses. The results of the survey and experiment are then analysed using a one-way Analysis Of Variance (ANOVA). Two main hypotheses are established as such:

$\mathrm{H}_{0}$ : There is no significant difference between the FUNDA OP-AMP and traditional lecturing methods in the fundamentals of operational amplifiers.

$\mathrm{H}_{1}$ : There is a significant difference between the FUNDA OP-AMP and traditional lecturing methods in the fundamentals of operational amplifiers.

The results of the ANOVA are then discussed with reference to the $p$-values obtained. If the $p$-value is lower than $0.05, \mathrm{H}_{0}$ is rejected. In contrast, if the $p$-value is above $0.05, \mathrm{H}_{1}$ is rejected. 


\section{Survey Findings}

The summaries of the participants' majoring, gender and status are tabulated in Table 1 to 3 .

Before any parametric analyses are done on the survey data, normality tests are carried out first. The Kolmogorov-Smirnov and Shapiro-Wilk normality tests are used to investigate the normality of the data for the following categories:

- FUNDA OP-AMP category results (E-learning)

- Traditional learning category results (Traditional)

Table 4 shows the normality test results for the survey data. It is found that $p$-values for all the categories defined are greater than 0.05 . This indicates that the possibility of the data set being not normal is rejected and the probability that the data is normal is greater than $95 \%$. Hence, the data is reliable enough for further parametric analyses.

Table 5 shows the Cronbach's alpha reliability test results for traditional lecturing and FUNDA OP-AMP lecturing methods. It is found that the alpha coefficients for both the variables are well above 0.7, indicating that the internal consistency and reliability of the data are acceptable.

Table 6 shows the results of the one-way ANOVA for the survey data. The parametric analyses using the one-way ANOVA show that the $p$-value of the relationship is less than 0.05 , indicating that the possibility of a significant difference existing between FUNDA OP-AMP and traditional lecturing methods in the fundamentals of operational amplifiers is greater than $95 \%$. Hence, the null hypothesis $\left(H_{0}\right)$ is rejected and the alternative hypothesis $\left(H_{1}\right)$ is accepted.

Table 1. Summary of majoring

\begin{tabular}{lccr}
\hline & Frequency & Valid percent & Cumulative percent \\
\hline Telecommunications & 32 & 53.3 & 53.3 \\
Robotics and Automations & 26 & 43.3 & 96.7 \\
Bioinstrumentation & 2 & 3.3 & 100.0 \\
Total & 60 & 100.0 & \\
\hline
\end{tabular}

Table 2. Summary of genders

\begin{tabular}{llcc}
\hline & Frequency & Valid percent & Cumulative percent \\
\hline Male & 42 & 70.0 & 70.0 \\
Female & 18 & 30.0 & 100.0 \\
Total & 60 & 100.0 & \\
\hline
\end{tabular}

Table 3. Summary of Status

\begin{tabular}{llcr}
\hline & Frequency & Valid percent & Cumulative percent \\
\hline Repeater & 14 & 23.3 & 23.3 \\
Non-Repeater & 46 & 76.7 & 100.0 \\
Total & 60 & 100.0 & \\
\hline
\end{tabular}

Table 4. Tests of Normality for Survey Data

\begin{tabular}{|c|c|c|c|c|c|c|}
\hline & \multicolumn{3}{|c|}{ Kolmogorov-smirnov $^{\mathrm{a}}$} & \multicolumn{3}{|c|}{ Shapiro-wilk } \\
\hline & Statistic & df & $p$-value & Statistic & $\mathrm{df}$ & $p$-value \\
\hline Results & 0.095 & 60 & $0.200^{*}$ & 0.947 & 60 & 0.140 \\
\hline
\end{tabular}

*. This is a lower bound of the true significance; a. Lilliefors Significance Correction

Table 5. Cronbach's Alpha Reliability Test Results

\begin{tabular}{lll}
\hline Variables & Cronbach's alpha & Number of items \\
\hline Traditional & 0.947 & 10 \\
E-learning & 0.963 & 10 \\
\hline
\end{tabular}

Table 6. One-Way ANOVA for Survey Data

\begin{tabular}{llrrll}
\hline & Sum of Squares & df & Mean Square & F & Sig. \\
\hline Between Groups & 23.438 & 1 & 23.438 & 28.385 & 0.000 \\
Within Groups & 47.891 & 58 & 0.826 & & \\
Total & 71.329 & 59 & & & \\
\hline
\end{tabular}


Further observations on the results in Table 7 show that the mean of the students' scores under the FUNDA OP-AMP learning group is higher than the mean of the students' scores under the traditional learning group (FO: 3.83, TL: 3.51 ). This clearly shows that the students' perception of the FUNDA OP-AMP lecturing methods is not only significantly different than that of traditional lecturing methods, but also condoned to be more important and agreeable in the fundamentals of operational amplifiers.

Supplementary analyses are also carried out to investigate if there are any significant effects from the majoring, status and gender of the participants on their perceptions of the importance of FUNDA OP-AMP and traditional lecturing methods. The one-way Analysis Of Variance (ANOVA) is used to examine the effects of gender, status and majoring on traditional and FUNDA OP-AMP methods.

Table 8 shows the effects of gender on traditional and FUNDA OP-AMP lecturing methods. It is found that the $p$-values are greater than 0.05 , implying that these two lecturing methods are not significantly affected by gender.
Table 9 reveals the results on how status affects traditional and FUNDA OP-AMP lecturing methods. Since the $p$-values are found to be greater than 0.05 , it can be concluded that the statuses of participants have no significant effects on both traditional and FUNDA OPAMP lecturing methods.

Table 10 presents the results on the effects of majoring on traditional and FUNDA OP-AMP lecturing methods. Based on the $p$-values which are higher than 0.05 , it is worth noting that there are also no significant effects from the majoring of the participants on traditional and FUNDA OP-AMP lecturing methods.

\section{Experimental Findings}

Similar normality tests are also done on the experimental data as a requirement before further parametric analyses. Table 11 shows the results of the normality tests conducted on the experimental data. It is found that $p$-values are greater than 0.05 , indicating that the probability of the data being normal is greater than $95 \%$. Hence, the data is reliable enough for further parametric analyses.

Table 7. Group Statistics for Survey Data

\begin{tabular}{llllll}
\hline \multicolumn{2}{l}{ Learning Method } & $\mathrm{N}$ & Mean & Std. Deviation & Std. Error Mean \\
\hline Scores & Traditional & 30 & 2.5800 & 1.11491 & 0.20355 \\
& E-learning & 30 & 3.8300 & 0.63905 & 0.11667 \\
\hline
\end{tabular}

Table 8. Effects of gender on traditional and FUNDA OP-AMP lecturing methods

\begin{tabular}{llrrlll}
\hline & & Sum of Squares & df & Mean Square & F & $p$-value \\
\hline Traditional & Between Groups & 1.128 & 2 & 0.564 & 0.932 & 0.406 \\
& Within Groups & 16.347 & 27 & 0.605 & & \\
& Total & 17.475 & 29 & & & \\
E-learning & 1.883 & 2 & 0.941 & 2.552 & 0.097 \\
& Between Groups & 9.960 & 27 & 0.369 & & \\
& Within Groups & 11.843 & 29 & & \\
& Total & & & & \\
\hline
\end{tabular}

Table 9. Effects of status on traditional and FUNDA OP-AMP lecturing methods

\begin{tabular}{|c|c|c|c|c|c|c|}
\hline & & Sum of squares & $\mathrm{df}$ & Mean Square & $\mathrm{F}$ & $p$-value \\
\hline \multirow[t]{3}{*}{ Traditional } & Between Groups & 0.023 & 1 & 0.023 & 0.037 & 0.849 \\
\hline & Within Groups & 17.452 & 28 & 0.623 & & \\
\hline & Total & 17.475 & 29 & & & \\
\hline \multirow[t]{3}{*}{ E-learning } & Between Groups & 0.372 & 1 & 0.372 & 0.907 & 0.349 \\
\hline & Within Groups & 11.471 & 28 & 0.410 & & \\
\hline & Total & 11.843 & 29 & & & \\
\hline
\end{tabular}

Table 10. Effects of majoring on traditional and FUNDA OP-AMP lecturing methods

\begin{tabular}{|c|c|c|c|c|c|c|}
\hline & & Sum of Squares & $\mathrm{df}$ & Mean Square & $\mathrm{F}$ & $p$-value \\
\hline \multirow[t]{3}{*}{ Traditional } & Between Groups & 0.827 & 1 & 0.827 & 1.391 & 0.248 \\
\hline & Within Groups & 16.648 & 28 & 0.595 & & \\
\hline & Total & 17.475 & 29 & & & \\
\hline \multirow[t]{3}{*}{ E-learning } & Between Groups & 1.450 & 1 & 1.450 & 3.908 & 0.058 \\
\hline & Within Groups & 10.393 & 28 & 0.371 & & \\
\hline & Total & 11.843 & 29 & & & \\
\hline
\end{tabular}


Table 11. Tests of normality for experimental data

\begin{tabular}{|c|c|c|c|c|c|c|}
\hline & \multicolumn{3}{|c|}{ Kolmogorov-Smirnov $^{\mathrm{a}}$} & \multicolumn{3}{|c|}{ Shapiro-Wilk } \\
\hline & Statistic & $\mathrm{df}$ & $p$-value & Statistic & $\mathrm{df}$ & $p$-value \\
\hline$\overline{\text { Results }}$ & 0.070 & 60 & $0.200^{*}$ & 0.980 & 60 & 0.439 \\
\hline
\end{tabular}

*. This is a lower bound of the true significance; a. Lilliefors Significance Correction

Table 12. One-way ANOVA for experimental data

\begin{tabular}{lcrrll}
\hline & Sum of Squares & df & Mean Square & F & Sig. \\
\hline Between Groups & 1162.568 & 1 & 1162.568 & 4.627 & 0.036 \\
Within Groups & 14571.550 & 58 & 251.234 & & \\
Total & 15734.119 & 59 & & & \\
\hline
\end{tabular}

Table 13. Group statistics for experimental data

\begin{tabular}{lllll}
\hline & $\mathrm{N}$ & Mean & Std. deviation & Std. error mean \\
\hline Traditional & 30 & 51.2080 & 14.07417 & 2.56958 \\
E-learning & 30 & 60.0117 & 17.44663 & 3.18530 \\
Total & 60 & 55.6098 & 16.33034 & 2.10824 \\
\hline
\end{tabular}

Table 12 presents the results of the one-way ANOVA for the experimental data. The results show that the $p$ value of the relationship is less than 0.05 , signifying that the likelihood of a significant difference existing between FUNDA OP-AMP and traditional lecturing methods in the fundamentals of operational amplifiers is greater than $95 \%$. Hence, the null hypothesis $\left(H_{0}\right)$ is rejected and the alternative hypothesis $\left(H_{1}\right)$ is accepted.

Additional observations on the results in Table 13 show that the mean of the students' results under the FUNDA OP-AMP learning group is higher than the mean of the students' results under the traditional learning group (FO: 60.01\% TL: 54.79\%). The difference between the two means is $9.10 \%$. This clearly shows that the students who undergo FUNDA OP-AMP lecturing methods not only have significantly different results compared to the results of traditional learners, but also exhibit better performance in the fundamentals of operational amplifiers than that of traditional learners.

One of the reasons pointed out by the students of the FUNDA OP-AMP module is that the e-learning lecturing strategies are easily understood since many illustrative examples are provided. The findings of this study are supported by other studies, which suggest that illustrative instructions (represented by videos) have a significant influence on e-learning acceptance in courses (Hrtonová et al., 2015). The illustrative instructions and examples provided also appear to be compatible with the students learning strategies. This finding is consistent with the findings of Islam (2016) who mentioned that if the e-learning programme is compatible with the learning method, the students' e-learning system utilisation will in all likelihood be materialised and this will result in improved academic performance. As evidence, researchers found that the statistical interaction between e-learning usage and compatibility is significant when it comes to the prediction of academic performance $(p<0.001)$ (DeLone and McLean, 2003; Islam, 2016).

The preceding findings appear to dispute the findings of Tawil et al. (2011) who found greater mean values for students' perception towards traditional lecturing methods than e-learning in Mathematics and Statistics. Traditional lecturing was also found to be better than elearning for trainees in dentistry (Browne et al., 2004). However, it can be argued that the current context of the module and type of e-learning system used are different from those implemented in the two foregoing studies. Hence, different results may be yielded across different study areas. Besides that, the experimental findings of this study also agreed with the survey findings.

It is undoubted that e-learning can be a strong proponent in the progression of modern teaching and learning methods. However, there have also been evidences from other researchers who suggested that exam passing rates increased by about $12 \%$ with the introduction of e-learning alongside traditional learning techniques (Deschacht and Goeman, 2015). A combination between the two would hence be termed blended learning. Thus, it is also important to note that a balance between traditional learning and e-learning is essential in order to reap the full competitive advantage of e-learning approaches.

\section{Conclusion}

This study has successfully proven that there is a significant difference between the FUNDA OP-AMP and traditional lecturing methods in the education of fundamentals of operational amplifiers among electronics engineering students. The study also revealed that the students' perception of the FUNDA OP-AMP 
lecturing methods was also condoned to be more important and agreeable in the instruction of fundamentals of operational amplifiers.

For future studies, it is suggested that more actual or experimental data (pertaining to the students' academic results) are captured and analysed in order to verify the significance of e-learning effects in Fundamentals of Operational Amplifier. Furthermore, the cluster of students that participate in the study could also be broadened to include other fields of engineering, such as Mechanical, Electrical, Civil, Manufacturing and Chemical engineering for instance. Overall, even though more analyses are required to verify the existing findings and innovate future discoveries in e-learning, this study still serves as preliminary evidence on the versatility and performance of e-learning techniques in electronics engineering subjects.

\section{Acknowledgment}

The authors would like to acknowledge the Faculty of Engineering and Technology, Multimedia University for the tremendous support given in conducting this research. This research was also supported by the Fundamental Research Grant Scheme (WBS. No.: MMUE/130109) secured by researchers from Multimedia University and provided by the Ministry of Education, Malaysia. The data presented, statements made and views expressed are solely the responsibility of the authors.

\section{Author's Contributions}

Wai Kit Wong: Initiated the idea of this research and was involved in the planning, execution and data collection of this study. He conducted some literature research as well. He also constructed and designed the protocol of the experiments and administered the elearning among the students for this study.

Poh Kiat Ng: Involved in the data analyses and write up of this study. He was also involved in a lot of the literature review compilation and methodology write-up.

\section{Ethics}

This article is original and contains unpublished material. The corresponding author confirms that all the other authors have read and approved the manuscript. Hence, no ethical issues are involved.

\section{References}

Bersin, J., 2004. The Blended Learning Book: Best Practices, Proven Methodologies and Lessons Learned. 1st Edn., John Wiley and Sons, Hoboken, ISBN-10: 0787976458, pp: 256.
Boyle, T., C. Bradley, P. Chalk, R. Jones and P. Pickard, 2003. Using blended learning to improve student success rates in learning to program. J. Educ. Media, 28: 165-178. DOI: $10.1080 / 1358165032000153160$

Browne, L., S. Mehra, R. Rattan and G. Thomas, 2004. Comparing lecture and e-learning as pedagogies for new and experienced professionals in dentistry. British Dental J., 197: 95-97. DOI: $10.1038 /$ sj.bdj.4811484

DeLone, W.H. and E.R. McLean, 2003. The Delone and Mclean model of information systems success: A ten-year update. J. Manage. Inform. Syst., 19: 9-30. DOI: $10.1080 / 07421222.2003 .11045748$

Deschacht, N. and K. Goeman, 2015. The effect of blended learning on course persistence and performance of adult learners: A difference-indifferences analysis. Comput. Educ., 87: 83-89. DOI: 10.1016/j.compedu.2015.03.020

Friesen, N., 2015. Report: Defining blended learning.

Garrison, R. and N.D. Vaughan, 2008. Blended Learning in Higher Education: Framework, Principles and Guidelines. 1st Edn., John Wiley and Sons, San Francisco, ISBN-10: 0787987700, pp: 245.

Graham, C.R., 2006. The Handbook of Blended Learning Global Perspectives, Local Designs. In: Blended Learning Systems: Definition, Current Trends and Future Directions, Graham, C.R. and C.J. Bonk (Eds.), Pfeiffer Publishing, San Francisco, pp: 1-32.

Hrtonová, N., J. Kohout, L. Rohlíková and J. Zounek, 2015. Factors influencing acceptance of e-learning by teachers in the Czech Republic. Comput. Hum. Behav., 51: 873-879. DOI: $10.1016 /$ j.chb.2014.11.018

Islam, A.K.M.N., 2016. E-learning system use and its outcomes: Moderating role of perceived compatibility. Telemat. Inform., 33: 48-55.

DOI: $10.1016 /$ j.tele.2015.06.010

Lim, D.H. and M.L. Morris, 2009. Learner and instructional factors influencing learning outcomes within a blended learning environment. Educ. Technol. Society, 12: 282-293.

Mortera-Gutierrez, F.J., 2006. Faculty best practices using blended learning in e-learning and face-to-face instruction. Int. J. E-Learn., 5: 313-337.

Rodríguez, J.C.F., J.J.R. Granados and F.M. Muñoz, 2013. Engineering education through eLearning technology in Spain. Int. J. Artificial Intell. Interactive Multimedia, 2: 46-50. DOI: $10.9781 /$ ijimai.2013.216

Soler, J., 2010. Entorno virtual para el aprendizaje y la evaluación automatic en bases de datos. PhD Thesis, University of Girona, Catalonia, Spain. 
Soler, J., F. Prados, I. Boada and J. Poch, 2006. Utilización de una plataforma e-learning en la docencia de bases de datos. Paper presented at the Actas de las XII Jornadas de la Enseñanza Universitaria de la Informática, Bilbao, Spain.

Tawil, N.M., N.A. Ismail, I. Shaari, H. Osman and Z.M. Nopiah et al., 2011. E-learning versus traditional method in teaching mathematics and statistics courses for engineering students in Universiti Kebangsaan Malaysia. Proceedings of the Congress of Teaching and Learning, (CTL' 11), Bangi, Malaysia.
Thorne, K., 2003. Blended Learning: How to Integrate Online and Traditional Learning. 1st Edn., Kogan Page Publishers, United Kingdom, ISBN-10: 0749439017, pp: 148

Ubell, R., 2000. Engineers turn to e-Learning. IEEE Spectrum, 37: 59-63. DOI: 10.1109/6.873919 